\title{
Theoretical investigations on the antioxidant potential of a non-phenolic compound thymoquinone: a DFT Approach
}

Jewel Hossen ( $\nabla$ jewelhossenruet@gmail.com )

Rajshahi University of Engineering and Technology https://orcid.org/0000-0003-4365-6272

M. Abbas Ali

Rajshahi University of Engineering and Technology

Sultanur Reza

Tokyo Metropolitan University - Minamiosawa Campus: Shuto Daigaku Tokyo

\section{Research Article}

Keywords: thymoquinone, DFT, antioxidant, free radical, theoretical investigation

Posted Date: March 30th, 2021

DOI: https://doi.org/10.21203/rs.3.rs-337734/v1

License: (c) (1) This work is licensed under a Creative Commons Attribution 4.0 International License.

Read Full License 


\section{Theoretical investigations on the antioxidant potential of a non-phenolic compound thymoquinone: a DFT}

Approach

Jewel Hossen ${ }^{1}$, M. Abbas Ali ${ }^{1}$, Sultanur Reza ${ }^{2}$

${ }^{1}$ Department of Chemistry, Rajshahi University of Engineering \& Technology, Rajshahi, Rajshahi-6204, Bangladesh

${ }^{2}$ Department of Chemistry, Tokyo Metropolitan University, Tokyo 192-0397, Japan.

Jewel Hossen, Department of Chemistry, Rajshahi University of Engineering \& Technology, Rajshahi, Rajshahi6204, Bangladesh, E-mail: jewelhossenruet@gmail.com, Orchid ID: 0000-0003-4365-6272

M. Abbas Ali, Department of Chemistry, Rajshahi University of Engineering \& Technology, Rajshahi, Rajshahi6204, Bangladesh, E-mail: radwiya44@yahoo.com

Department of Chemistry, Tokyo Metropolitan University, Tokyo 192-0397, Japan, E-mail: sreza2002@yahoo.com

Corresponding author:

Jewel Hossen, Department of Chemistry, Rajshahi University of Engineering \& Technology, Rajshahi, Rajshahi6204, Bangladesh, E-mail: jewelhossenruet@gmail.com, Orchid ID: 0000-0003-4365-6272 


\begin{abstract}
Thymoquinone (TQ) is a natural compound occurred in black cumin (Nigella sativa L.), which possesses potent antioxidant activity without having any phenolic hydroxyl group believed to be responsible for antioxidant activity of a molecule. In the present study, computational calculation based on Density Functional Theory (DFT) have been executed to assess systematically the worth of antioxidant behavior of this compound. Geometrical characteristics, HOMO-LUMO and MEP surface have been studied. Thermochemical parameters correlated to the leading antioxidant mechanisms such as HAT, SETPT and SPLET have been studied in gas and water media. In addition, the changes of thermochemical parameters such as $\Delta \mathrm{G}$ and $\Delta \mathrm{H}$ have been computed for HA from TQ to hydroxyl radical in gas and water phases to investigate its free radical scavenging potency. The low and comparable values of BDE, PDE, IP, PA and ETE suggest the antioxidant activity. The $\Delta \mathrm{G}$ and $\Delta \mathrm{H}$ also convey apposite thermodynamic evidence in favor of antiradical capability of TQ. The attack of the free radical takes place preferentially at $3 \mathrm{CH}$ position of the molecule.
\end{abstract}

Keywords: thymoquinone, DFT, antioxidant, free radical, theoretical investigation

\title{
Introduction
}

Free radicals form in biological reactions in living cells [1], but some external factors such as radiation, pollutants, physical stress, pesticides, several treatments etc. also cause its formation [2]. The highly reactive free radicals can initiate chain reactions interacting with proteins, lipids and DNA, and thereby damage the tissues [3]. Foods containing antioxidant compounds play a crucial role to check the human illnesses caused by the detrimental effects of free radicals [4]. Polyphenols, phenolic acids and flavonoids either synthetic or natural can guard biomolecules against unexpected oxidative damage triggered by the free radicals. Thus, they inhibit the oxidative mechanisms that lead to degenerative diseases [5][6].

Thymoquinone (TQ) is an active component of black cumin (Nigella sativa L.) essential oil possessing antineoplastic, anti-inflammatory, neuro- and hepato-protective properties. These properties are attributed to the antioxidant potential of TQ, which seems to be unlikely due to its structure [7]. It has a number of pharmacological properties, among them antioxidant activity is the most important one [8]. It is a common belief that, only the compounds having phenolic OH groups are responsible for antioxidant activity and/or free radical scavenging power [9][10][11][12]. Recently it has been proved that, compound without phenolic $\mathrm{OH}$ group can pose antioxidant or antiradical capability. Baschieri et al explained the antioxidant activity of three common non-phenolic terpenoids [13]. Several investigations have 
also exposed that some $\mathrm{CH}$ bonds contribute to the antioxidant characteristics of natural products [14][15]. Antioxidant potential of TQ is well recognized in various literature [16][17][18][19], although it also does not contain any phenolic $\mathrm{OH}$ group.

In computational method, the antioxidant activity of a compound can be thermodynamically evaluated by some physicochemical descriptors such as bond dissociation enthalpy (BDE), proton dissociation enthalpy (PDE), proton affinity (PA), ionization potential (IP), electron transfer enthalpy (ETE), hardness, softness and electronegativity. Recently, computational techniques, especially DFT method, have been commendably applied to determine these thermodynamic parameters of antioxidant molecules [3][20].

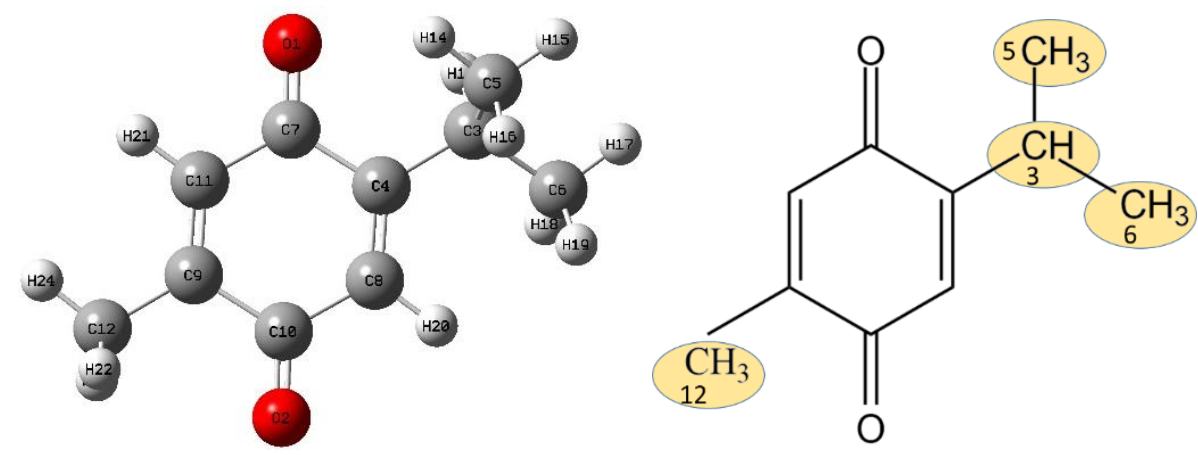

Figure 1. Optimized (left) and schematic structures of TQ and possible groups considered for antioxidant action (right)

However, so far we have studied, no or less computational study on the antioxidant power of TQ molecule (Figure 1) has been reported till date. The objective of this article is to apply the computational methods to evaluate the antioxidant ability of TQ in connection to its non-phenolic structure. In addition, the stability of the formed radicals from the entitled compound has been explained to govern the comparative radical scavenging ability of the groups undertaken in this study.

In the modern computational platform, antioxidant ability of a compound can be successfully determined by monitoring some specific chemical reaction mechanisms. Among them, hydrogen atom transfer (HAT) is familiar one and defined as follows:

$\mathrm{AH}+\mathrm{R}^{\bullet} \rightarrow \mathrm{A}^{\bullet}+\mathrm{RH}$ 
Which relates to the bond dissociation enthalpy (BDE) of the corresponding (A-H) bond that presents direct relation to experimental determination of antioxidant activity [21].

$\mathrm{BDE}=\mathrm{H}\left(\mathrm{A}^{\bullet}\right)+\mathrm{H}\left(\mathrm{H}^{\bullet}\right)-\mathrm{H}(\mathrm{AH})$

Another important mechanism is the single electron transfer-proton transfer mechanism (SETPT) in which the IP of the molecule and PDE from $\mathrm{AH}^{\bullet+}$ are accounted [3].

$\mathrm{AH}+\mathrm{R}^{\bullet} \rightarrow \mathrm{AH}^{\bullet+}+\mathrm{R}^{-} \rightarrow \mathrm{A}^{\bullet}+\mathrm{RH}$

$\mathrm{IP}=\mathrm{H}\left(\mathrm{AH}^{\bullet+}\right)+\mathrm{H}(\mathrm{e})-\mathrm{H}(\mathrm{AH})$

$\mathrm{PDE}=\mathrm{H}\left(\mathrm{A}^{\bullet}\right)+\mathrm{H}\left(\mathrm{H}^{+}\right)-\mathrm{H}\left(\mathrm{AH}^{\bullet+}\right)$

The third pathway is sequential proton loss electron transfer (SPLET) mechanism to investigate the antioxidant potential of a molecule [22]. SPLET is given by:

$\mathrm{AH} \rightarrow \mathrm{A}^{-}+\mathrm{H}^{+}$

$\mathrm{PA}=\mathrm{H}\left(\mathrm{A}^{-}\right)+\mathrm{H}\left(\mathrm{H}^{+}\right)-\mathrm{H}(\mathrm{AH})$

$\mathrm{A}^{-}+\mathrm{R}^{\bullet} \rightarrow \mathrm{A}^{\bullet}+\mathrm{R}^{-}$

$\mathrm{ETE}=\mathrm{H}\left(\mathrm{A}^{\bullet}\right)+\mathrm{H}(\mathrm{e})-\mathrm{H}\left(\mathrm{A}^{-}\right)$

The reactivity and stability of a molecule are considered as significant factors to determine the antioxidant potency which depend upon the difference $(\Delta \mathrm{E})$ between lowest unoccupied molecular orbital (LUMO) and highest occupied molecular orbital (HOMO) [23]. Large $\Delta \mathrm{E}$ indicates low reactivity and high stability of the compound. The chemical reactivity also rest on the synergistic effects of different parameters. The $\mathrm{E}_{\mathrm{HO} о}$ energy of a molecule show the electron donating ability whereas $\mathrm{E}_{\mathrm{LUMO}}$ characterizes electrons accepting ability. Ionization potential (IP) and electron affinity (EA) are also roughly accompanying with Eномо and ELUмo according to Janak's Theorem [24].

$$
\begin{aligned}
& I P=-E_{\text {номо }} \\
& E A=-E_{\text {LUMO }}
\end{aligned}
$$

Hardness $(\eta)$ is defined as resisting power towards the polarization of electron cloud of a chemical species [25]. 


$$
\begin{gathered}
\text { Hardness, } \eta=\frac{I P-E A}{2} \\
\text { or Hardness, } \eta=\frac{E_{\text {LUMO }}-E_{\text {HOMO }}}{2}
\end{gathered}
$$

Softness is just reciprocal of the hardness [26].

$$
\text { Softness, } \sigma=\frac{1}{\eta}
$$

Electronegativity $(\chi)$ can be described as the ability of an atom to have more attraction to covalently bonded shared electrons toward itself. It is computed as follows:

$$
\text { Electronegativity, } \chi=\frac{-\left(E_{\text {Номо }}+E_{\text {LUмо }}\right)}{2}
$$

Thus, antioxidant power of a compound can be estimated by taking account all the possible physicochemical characteristics such as geometrical, thermochemical and orbital.

\section{Computational details}

All calculations were accomplished in Gaussian 9 software tool [15]. The structures of TQ, its ions and radicals were optimized using the functional B3LYP [27] and basis set 6-311+G(d,p) in gas phase and water medium. This methodology has demonstrated good agreement between theoretical and experimental outcomes [28][29]. All the optimized structures were accepted through vibrational frequency analysis (no imaginary frequency was found for optimized structure). The thermochemical parameters (BDE, IP, PDE, PA, ETE) associated with antioxidant mechanisms have been calculated for the TQ molecule as follows [30][31]. Here in the equations, TQ has been written as (TQ-H) for better understanding.

$\mathrm{BDE}=\mathrm{H}\left(\mathrm{TQ}^{\bullet}\right)+\mathrm{H}\left(\mathrm{H}^{\bullet}\right)-\mathrm{H}(\mathrm{TQ}-\mathrm{H})$

$\mathrm{IP}=\mathrm{H}\left(\mathrm{TQ}-\mathrm{H}^{\bullet+}\right)+\mathrm{H}(\mathrm{e})-\mathrm{H}(\mathrm{TQ}-\mathrm{H})$

$\mathrm{PDE}=\mathrm{H}\left(\mathrm{TQ}^{\bullet}\right)+\mathrm{H}\left(\mathrm{H}^{+}\right)-\mathrm{H}\left(\mathrm{TQ}-\mathrm{H}^{\bullet+}\right)$

$\mathrm{PA}=\mathrm{H}\left(\mathrm{TQ}^{-}\right)+\mathrm{H}\left(\mathrm{H}^{+}\right)-\mathrm{H}(\mathrm{TQ}-\mathrm{H})$

$\mathrm{ETE}=\mathrm{H}\left(\mathrm{TQ}^{\bullet}\right)+\mathrm{H}(\mathrm{e})-\mathrm{H}\left(\mathrm{TQ}^{-}\right)$ 
where $\mathrm{H}\left(\mathrm{TQ}^{\bullet}\right)$ and $\mathrm{H}\left(\mathrm{H}^{\bullet}\right)$ are the enthalpies of $\mathrm{TQ} \bullet$ radical and $\mathrm{H}$ atom respectively, $\mathrm{H}(\mathrm{TQ}-\mathrm{H})$ and $\mathrm{H}(\mathrm{e})$ are the enthalpies of neutral TQ molecule and electron respectively, $\mathrm{H}\left(\mathrm{TQ}-\mathrm{H}^{\bullet+}\right)$ is the enthalpy of radical cation, $\mathrm{H}\left(\mathrm{H}^{+}\right)$is the enthalpy of proton, and $\mathrm{H}\left(\mathrm{TQ}^{-}\right)$is the enthalpy of anion formed after elimination of a proton.

In order to calculate the reaction enthalpies, it needs the enthalpies of hydrogen atom, proton and electron. The gas phase values were taken from previous calculations [32] [33]. Enthalpies of proton and electron in water were taken from reference [34], and that of hydrogen atom from reference [35].

Changes of Gibbs free energy $(\Delta \mathrm{G})$ and enthalpy $(\Delta \mathrm{H})$ of the hydroxyl radical scavenging reaction by TQ were calculated according to the simple equations of thermochemistry as follows.

Reactions: $\quad(\mathrm{TQ}-\mathrm{H})+\mathrm{OH}^{\bullet}=\mathrm{TQ}^{\bullet}+\mathrm{H}_{2} \mathrm{O}$

$$
(\mathrm{TQ}-\mathrm{H})+\mathrm{OH}^{\bullet}=(\mathrm{TQ}-\mathrm{H})^{+\bullet}+\mathrm{OH}^{-}
$$

Gibbs free energy changes for the reactions

$\Delta \mathrm{G}=\left\{\mathrm{G}\left(\mathrm{TQ}^{\bullet}\right)+\mathrm{G}\left(\mathrm{H}_{2} \mathrm{O}\right)\right\}-\left\{\mathrm{G}(\mathrm{TQ}-\mathrm{H})+\mathrm{G}\left(\mathrm{OH}^{\bullet}\right)\right\}$

$\Delta \mathrm{G}=\left\{\mathrm{G}(\mathrm{TQ}-\mathrm{H})^{+\bullet}+\mathrm{G}\left(\mathrm{HO}^{-}\right)\right\}-\left\{\mathrm{G}(\mathrm{TQ}-\mathrm{H})+\mathrm{G}\left(\mathrm{OH}^{\bullet}\right)\right\}$ respectively

and similarly enthalpy changes for the above reactions

$\Delta \mathrm{H}=\left\{\mathrm{H}\left(\mathrm{TQ}^{\bullet}\right)+\mathrm{H}\left(\mathrm{H}_{2} \mathrm{O}\right)\right\}-\left\{\mathrm{H}(\mathrm{TQ}-\mathrm{H})+\mathrm{H}\left(\mathrm{OH}^{\bullet}\right)\right\}$

$\Delta \mathrm{H}=\left\{\mathrm{H}(\mathrm{TQ}-\mathrm{H})^{+\bullet}+\mathrm{H}\left(\mathrm{HO}^{-}\right)\right\}-\left\{\mathrm{H}(\mathrm{TQ}-\mathrm{H})+\mathrm{H}\left(\mathrm{OH}^{\bullet}\right)\right\}$ respectively.

Where, $\mathrm{G}(\mathrm{X})$ and $\mathrm{H}(\mathrm{X})$ are the free energy and enthalpy respectively obtained from the optimized geometry of the associated species $\mathrm{X}$ calculated at the same level of theory.

\section{Spin density analysis}

Spin density distribution is an important quantum property in the estimation of free radical scavenging power of a compound. The stability of a free radical largely depends upon the electron spin density distribution over the radical. Higher delocalization of spin density in the radical reflects its easier formation as well as higher stability [36]. 


\section{Results and Discussions}

\section{Geometry optimization and conformational analysis}

To know the antioxidant behavior of a compound, it is highly recommended to examine its geometrical conformation. For this reason, the geometrical structures of TQ, its radicals, cation, and anions were optimized in the gas and water at B3LYP/6-311+G(d,p) condition using DFT. Some characteristic such as bond length, bond angle and torsion angle of the entitled compound have been tabulated in Table 1. The optimized structure with atom numbering and the schematic projection of TQ are shown in Figure 1. Very little or no change in the geometrical parameters was observed for optimized TQ molecule in gas phase and water media. Energy changes along the optimization process are depicted in the figure (S-Figure 1). Optimized structure of TQ in aqueous phase contains $5.39 \mathrm{kcal} / \mathrm{mole}$ less energy than that in gas phase.

Table 1. Geometrical parameters of TQ molecule optimized at the level of B3LYP/6-311+G (d, p) in gas phase and water

\begin{tabular}{|c|c|c|c|c|c|c|c|c|c|}
\hline & Bonc & length & & Bond a & gle (degre & & Dihedral & ngle (degre & \\
\hline & Bond & Gas & Water & Angle & Gas & Water & Dihedral angle & Gas & Water \\
\hline & O1-C7 & 1.222 & 1.225 & $\mathrm{O} 1-\mathrm{C} 7-\mathrm{C} 4$ & 121.117 & 121.044 & O1-C7-C4-C3 & 3.219 & 3.574 \\
\hline & $\mathrm{O} 2-\mathrm{C} 10$ & 1.222 & 1.226 & O1-C10-C9 & 120.724 & 120.671 & $\mathrm{O} 2-\mathrm{C} 10-\mathrm{C} 9-\mathrm{C} 12$ & -0.015 & 0.118 \\
\hline$\partial$ & $\mathrm{C} 3-\mathrm{C} 4$ & 1.512 & 1.512 & C9-C12-H23 & 110.543 & 110.576 & C8-C4-C3-C5 & -102.589 & -101.428 \\
\hline$\cong$ & C9-C12 & 1.497 & 1.496 & $\mathrm{H} 24-\mathrm{C} 12-\mathrm{H} 23$ & 109.153 & 108.987 & C7-C4-C3-C5 & 76.885 & 77.960 \\
\hline $\bar{\Xi}$ & $\mathrm{C} 3-\mathrm{C} 5$ & 1.546 & 1.546 & C4-C3-H13 & 106.172 & 106.320 & $\mathrm{C} 10-\mathrm{C} 9-\mathrm{C} 12-\mathrm{H} 22$ & 58.506 & 58.950 \\
\hline હ & $\mathrm{C} 3-\mathrm{C} 6$ & 1.533 & 1.533 & $\mathrm{C} 4-\mathrm{C} 3-\mathrm{C} 5$ & 110.079 & 110.005 & C11-C9-C12-H24 & -0.324 & -0.170 \\
\hline & $\mathrm{C} 12-\mathrm{H} 23$ & 1.094 & 1.094 & C4-C3-C6 & 113.760 & 113.778 & H13-C3-C6-H17 & 56.499 & 56.414 \\
\hline & C3-H13 & 1.095 & 1.095 & C5-C3-C6 & 110.944 & 110.866 & H13-C3-C5-H14 & 58.247 & 59.403 \\
\hline & $\mathrm{C} 5-\mathrm{H} 15$ & 1.093 & 1.093 & C5-C3-H13 & 106.850 & 107.098 & C6-C3-C5-H15 & 56.938 & 57.676 \\
\hline & C6-H19 & 1.094 & 1.094 & H18-C6-H19 & 108.151 & 108.256 & C5-C3-C6-H17 & -60.700 & -60.896 \\
\hline
\end{tabular}

After withdrawal of proton from $3 \mathrm{CH}$ bond, permanent carbon-carbon double $(\mathrm{C}=\mathrm{C})$ bond formed between $\mathrm{C} 3$ and C4 with delocalization of $\pi$-electrons around $\mathrm{C} 4-\mathrm{C} 8-\mathrm{C} 10$ of the ring (S-Figure 3) and in case of 3CH-radical, 
delocalization of electrons is distributed over C3-C4-C8-C10 areas both in gas and water phase (S-Figure 2). One important change observed after removal of proton and hydrogen atom from $3 \mathrm{CH}$ group is that, the $5 \mathrm{CH}_{3}$ and $6 \mathrm{CH}_{3}$ groups came to the same plane of the ring that means the whole structure became planer (S-Figure 2 and S-Figure 3). Due to the subtraction of proton from $12 \mathrm{CH}_{3}$, carbon-carbon double bond observed between $\mathrm{C} 12$ and $\mathrm{C} 9$ with delocalization of electrons around C9-C11-C7 of the ring in both phases studied and similar changes were found for $12 \mathrm{CH}_{3}$ radical. These delocalization of electrons recommends in favor of antioxidant potential of the studied molecule [31]. But such significant changes were not observed for the elimination of proton and hydrogen atom from $5 \mathrm{CH}_{3}$ and $6 \mathrm{CH}_{3}$ groups of TQ.

\section{Bond dissociation enthalpy and spin density: HAT mechanism}

Bond dissociation enthalpy (BDE) plays a vital role in the evaluation of antioxidant potential of a compound as it describes the hydrogen atom donating ability and formation of a stable radical. The lower the BDE, the higher the hydrogen atom donating tendency as well as the higher free radical scavenging power [37]. The BDEs for concerned (C-H) bonds of TQ were calculated in gas and aqueous phases at B3LYP/6-311+G(d,p) level in DFT and presented in Table 2. From the calculated values of $\mathrm{BDE}$ for the possible functional groups of TQ, it has been found that, $3 \mathrm{CH}$, $12 \mathrm{CH}_{3}, 5 \mathrm{CH}_{3}$, and $6 \mathrm{CH}_{3}$ possess BDEs of $77.40,83.68,100.25,100.19 \mathrm{kcal} / \mathrm{mole}$ in gas phase and 75.80, 83.07, 100.15 , and $100.26 \mathrm{kcal} / \mathrm{mole}$ in water medium respectively. The values of BDE of the groups in the water medium has been decreased slightly which shows very good agreement with a previous study [3]. The values of BDE of group $12 \mathrm{CH}_{3}$ and $3 \mathrm{CH}$ are less than or close to the literature values computed for other compounds such as ascorbic acid, gallic acid [3], myricetin [38] and myricetin 3,4-di-O- $\alpha$-Lrhamnopyranoside [39]. The comparable values of BDE of HAT reaction calculated for TQ suggest its antioxidant potential through free radical scavenging mechanism.

Table 2. BDE for different C-H bonds of TQ calculated at B3LYP/6-311+G(d,p) level

\begin{tabular}{|c|c|c|c|c|c|c|}
\hline \multirow{2}{*}{ Group of TQ } & \multicolumn{2}{|c|}{ BDE (kcal/mole) } & \multicolumn{2}{c|}{$\Delta$ E for radical } & \multicolumn{2}{c|}{$\Delta$ E for anion } \\
\cline { 2 - 7 } & Gas phase & Water & Gas phase & Water & Gas phase & Water \\
\hline $3 \mathrm{CH}$ & 77.40 & 75.80 & 389.55 & 387.95 & 340.87 & 293.92 \\
\hline $12 \mathrm{CH}_{3}$ & 83.68 & 83.07 & 395.84 & 395.22 & 341.63 & 296.30 \\
\hline $5 \mathrm{CH}_{3}$ & 100.25 & 100.15 & 412.40 & 412.30 & 356.40 & 306.98 \\
\hline
\end{tabular}




\begin{tabular}{|c|c|c|c|c|c|c|}
\hline $6 \mathrm{CH}_{3}$ & 100.19 & 100.26 & 412.34 & 412.41 & 380.25 & 338.24 \\
\hline $\begin{array}{c}\text { Ascorbic acid } \\
\text { 3-OH }\end{array}$ & 81.80 & 77.6 & & & & \\
\hline Gallic acid & 87.40 & 85.3 & & & & \\
3-OH & 79.10 & 79.2 & & & & \\
\hline 4-OH & & & & & \\
\hline
\end{tabular}

The values of ascorbic acid and Gallic acid were taken from the reference [3].

In order to elucidate the changes in BDEs, the distributions of spin density of the corresponding $\mathrm{TQ}^{\bullet}$ radicals were figured out in the gas phase and water phase, and presented in Figure 3. It is a reasonably trustworthy quantity to explain the stability of the free radical. Radical with higher delocalization of spin density is more stable [40]. As displayed in Figure 2, after deduction of a hydrogen atom from the functional groups studied here, $3 \mathrm{CH}$ and $12 \mathrm{CH}_{3}$ groups had the most delocalized spin density in the corresponding radical which are in good concordance with their sequence of BDE values. 


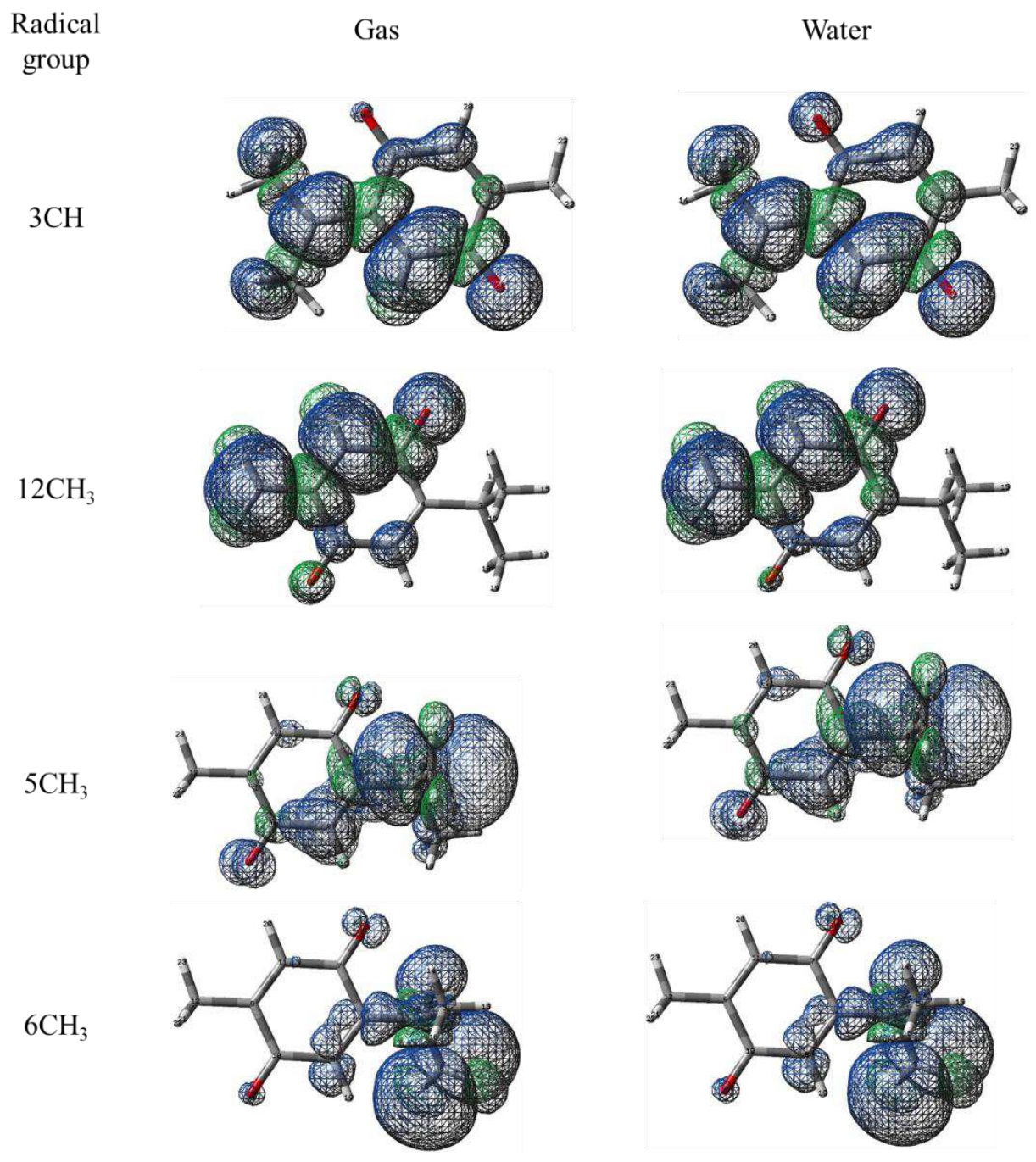

Figure 2. Spin density distribution of the radicals formed after elimination of hydrogen atom from the functional groups concerned.

The spin density for $3 \mathrm{CH}$ and $12 \mathrm{CH}_{3}$ radicals are more distributed whereas those for $5 \mathrm{CH}_{3}$ and $6 \mathrm{CH}_{3}$ are more localized around the concerned groups. This can also reflect the evidence for the more free radical scavenging strength of the TQ molecule with respect to $3 \mathrm{CH}$ and $12 \mathrm{CH}_{3}$ groups. This tendency is almost similar for all the radicals in both gas and water media. As can be concluded from the above discussions that, the $3 \mathrm{CH}$ and $12 \mathrm{CH}_{3}$ groups mainly contribute to the antioxidant activity of TQ, while the other groups play little role via HAT mechanism.

Ionization potential and proton dissociation enthalpy: SETPT mechanism 
SETPT mechanism comprises two stages: donating electron to a free radical $\mathrm{R}^{\bullet}$ and subsequently transfer a proton to the anion. In order to justify the possibility of these reactions, it requires to determine ionization potential (IP) for the former step and proton dissociation enthalpy (PDE) for the later one. SETPT mechanism combines IP and PDE to define the antioxidant activity of a compound. The lower IP and PDE values represent higher antioxidant tendency through SETPT scheme [31]. The Table 3 represents the IP of TQ molecule and PDEs of its different $\mathrm{CH}$ bonds. The PDE value is lowest (193.04 and $220.88 \mathrm{kcal} / \mathrm{mole}$ in gas and water respectively) for $\mathrm{CH}$ bond of $3 \mathrm{CH}$ group and highest, $215.88 \mathrm{kcal} / \mathrm{mole}$ of $5 \mathrm{CH}_{3}$ in gas, and $245.34 \mathrm{kcal} / \mathrm{mole}$ of $6 \mathrm{CH}_{3}$ in water. The PDE value of $\mathrm{CH}$ bond of group $3 \mathrm{CH}$ is less than that of literature value of other substances demanding antioxidant capacity [41], [42]. The lower value of $\mathrm{PDE}$ of $3 \mathrm{CH}$ bond may be due to the two electron donating methyl groups attached to the carbon atom. But here the IP values of TQ have been found to be a bit higher in comparison to literature [3]. It can be explained that, it is slightly difficult for TQ do donate electron. The electron-donating ability is related to an extended electronic delocalization over the entire molecule. A molecule having a high degree of $\pi$-delocalization is more active [43]. From the above discussion it can be said that, TQ is less likely to pose SETPT formalism of antioxidant behavior.

Table 3. PDE and ETE values of TQ calculated at B3LYP/6-311+G(d,p) level of theory

\begin{tabular}{|c|c|c|c|c|}
\hline \multirow{2}{*}{ TQ group } & \multicolumn{2}{|c|}{$\operatorname{PDE}(\mathrm{kcal} / \mathrm{mole})$} & \multicolumn{2}{|c|}{ IP (kcal/mole) } \\
\hline & Gas phase & Water & Gas phase & Water \\
\hline $3 \mathrm{CH}$ & 193.04 & 220.88 & 198.73 & 169.28 \\
\hline $12 \mathrm{CH}_{3}$ & 199.32 & 228.15 & & \\
\hline $5 \mathrm{CH}_{3}$ & 215.88 & 245.23 & & \\
\hline $6 \mathrm{CH}_{3}$ & 215.83 & 245.34 & & \\
\hline \multicolumn{5}{|l|}{ Ascorbic acid } \\
\hline $3-\mathrm{OH}$ & 202.92 & & 191.82 & \\
\hline \multicolumn{5}{|l|}{ Gallic acid } \\
\hline $3-\mathrm{OH}$ & 212.60 & & 189.20 & \\
\hline $4-\mathrm{OH}$ & 204.30 & & & \\
\hline
\end{tabular}

The values of ascorbic acid and Gallic acid were taken from the reference [3].

Proton affinity and electron transfer enthalpy: SPLET mechanism 
The third mechanism of the antioxidant activity (SPLET) is characterized by the proton affinity (PA) value which corresponds to the enthalpy of proton dissociation from the neutral molecule, and the electron transfer enthalpy (ETE) value that corresponds to the enthalpy of transfer of an electron from the antioxidant anion to the free radical. The lower PA and ETE values is characteristic of higher antioxidant activity through the SPLET mechanism [31]. The calculated PA and ETE values for TQ in the gas phase and water are given in Table 4. The PA values for the studied $\mathrm{CH}$ bond of TQ are comparable to the literature value [3]. PA values of TQ are lower in water than in gas phase which is in good consistent with previous literature [31]. The PA values are in the range of 342-381 kcal/mole in gas phase and $295-339 \mathrm{kcal} / \mathrm{mole}$ in water. The minimum $(342.35 \mathrm{kcal} / \mathrm{mole}) \mathrm{PA}$ has been found for $\mathrm{CH}$ bond of $3 \mathrm{CH}$ group and maximum $(381.73 \mathrm{kcal} / \mathrm{mole})$ of $6 \mathrm{CH}_{3}$ group in gas phase. The lower value of $\mathrm{PA}$ for $3 \mathrm{CH}$ can be due to the electron pushing character of two methyl groups attached herewith. The ETE values of various CH bonds of TQ are lower in gas than in water which is also in agreement with literature [43]. The ETEs are in the range of 32-56 kcal/mole in gas whereas in the range of $74-106 \mathrm{kcal} / \mathrm{mole}$ in water. This also shows very good agreement with literature of similar study [31]. These values are less than or close to the corresponding values of another similar research [40] [43]. Lowest PA values were observed for 3CH group both in gas and water, and lowest ETE values were computed for $6 \mathrm{CH}_{3}$ group both in gas and water. These data clearly reveal the capability of TQ as a potential antioxidant molecule.

Table 4. PA and ETE values of TQ in gas phase and water calculated at B3LYP/6-311+G(d,p)

\begin{tabular}{|c|c|c|c|c|}
\hline \multirow{2}{*}{ Group of TQ } & \multicolumn{2}{|c|}{ PA (kcal/mole) } & \multicolumn{2}{|c|}{ ETE (kcal/mole) } \\
\hline & Gas phase & Water & Gas phase & Water \\
\hline $3 \mathrm{CH}$ & 342.35 & 295.40 & 49.42 & 94.77 \\
\hline $12 \mathrm{CH}_{3}$ & 343.12 & 297.79 & 54.94 & 99.65 \\
\hline $5 \mathrm{CH}_{3}$ & 357.88 & 308.46 & 56.74 & 106.06 \\
\hline $6 \mathrm{CH}_{3}$ & 381.73 & 339.72 & 32.84 & 74.90 \\
\hline \multicolumn{5}{|l|}{ Ascorbic acid } \\
\hline $3-\mathrm{OH}$ & 328.98 & & 65.76 & \\
\hline \multicolumn{5}{|l|}{ Gallic acid } \\
\hline $3-\mathrm{OH}$ & 329.00 & & 72.90 & \\
\hline
\end{tabular}


The values of ascorbic acid and Gallic acid were taken from the reference [3].

\section{Frontier molecular orbitals (HOMO - LUMO)}

Frontier molecular orbitals (FMO) or HOMO and LUMO denote the highest occupied molecular orbital and the lowest unoccupied molecular orbital respectively. FMOs are important parameters to predict the antioxidant activity of a compound [44]. The Еном represents the ability of electron donation, because it is energetically easiest to take away electron from this orbital, whereas $\mathrm{E}_{\text {LUмо }}$ shows the capability to accept electron [45]. Molecules with lower $\mathrm{E}_{\text {Hомо }}$ are more stable and less expected to give electrons and the shape of HOMO determines the sites for free radical attack [38]. The calculated FMO of TQ molecule in gas and water phases are represented in Figure 3. FMO with traditional $\pi$-like molecular orbital appearance and distribution approximately over the entire molecule suggests antioxidant power of the molecule [31]. As shown in Figure 3, HOMO and LUMO orbitals are distributed on an average over the entire TQ structure with little above the $5 \mathrm{CH}_{3}$ and $6 \mathrm{CH}_{3}$ groups, which directs their less involvement in antioxidant reactions. HOMO orbital is well distributed over $3 \mathrm{CH}$ and $12 \mathrm{CH}_{3}$ groups, suggesting the probable contribution to antioxidant activity. The HOMO-1 orbital is mostly contributed to the $\pi$ orbitals of double bonds and oxygen atoms.

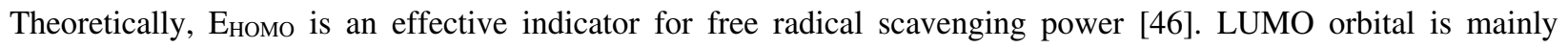
distributed over the ring with the two oxygen atoms. Small energy gap between LUMO and HOMO infers the softness whereas large gap indicates the hardness of the molecule. Soft molecule is more reactive than hard one and it can donate electron more easily to the receiver. [47]. The global reactivity descriptors derived from $\mathrm{E}_{\text {Hомо }}$ and $\mathrm{E}_{\mathrm{LUMO}}$ are calculated and presented in Table 5. The comfort of electron donation depends on the electronegativity. The values of hardness, softness, IP, EA and electronegativity of TQ calculated in this study are very close to those computed for other molecules claimed as potential antioxidant [3].

Table 5. HUMO-LUMO energy and global reactivity descriptor values of TQ

\begin{tabular}{llcc} 
& \multirow{2}{*}{ Symbol and formula } & \multicolumn{2}{c}{ Value, eV } \\
\cline { 3 - 4 } & & Gas phase & Water \\
\hline LUMO energy $(\mathrm{eV})$ & ELUMO & -3.575 & -3.646
\end{tabular}




\begin{tabular}{|c|c|c|c|}
\hline HOMO energy (eV) & $\mathrm{E}_{\text {номо }}$ & -7.447 & -7.564 \\
\hline Energy gap (eV) & $\mathrm{E}_{\mathrm{g}}=\mathrm{E}_{\mathrm{LUMO}}-\mathrm{E}_{\text {HOMO }}$ & 3.872 & 3.918 \\
\hline Ionization potential & $\mathrm{IP}=-\mathrm{E}_{\text {Номо }}$ & 7.448 & 7.565 \\
\hline Electron affinity & $\mathrm{EA}=-\mathrm{E}_{\mathrm{LUMO}}$ & 3.575 & 3.646 \\
\hline Global hardness & $\eta=\left(\mathrm{E}_{\mathrm{LUMO}}-\mathrm{E}_{\mathrm{HOMO}}\right) / 2$ & 1.936 & 1.959 \\
\hline Softness & $\sigma=1 / \eta$ & 0.516 & 0.510 \\
\hline Chemical potential & $\mu=\left(\mathrm{E}_{\mathrm{LUMO}}+\mathrm{E}_{\text {Номо }}\right) / 2$ & -5.511 & -5.605 \\
\hline Electrophilicity & $\psi=\mu^{2} / 2 \eta$ & 7.845 & 8.019 \\
\hline Electronegativity & $\chi=-\mu$ & 5.511 & 5.605 \\
\hline
\end{tabular}

\section{Molecular electrostatic potential}

Molecular electrostatic potential (MEP) is another supportive aspect for investigating and forecasting antioxidant capacity of a compound. The electron-deficient (positive) sites are the most likely sites for free radical attack [31]. It can be seen from the Figure 4 that, most electron-rich (negative) surfaces are positioned over the oxygen atoms whereas the electron-deficient (positive) surfaces are located around the hydrogen atoms of the ring and the side chains in both gas phase and water. These upshots could be useful in prediction of the positions for free radical attack of TQ molecule. However the antioxidant reaction is an intricate and multifarious process and could be subjective to numerous aspects [48]. 

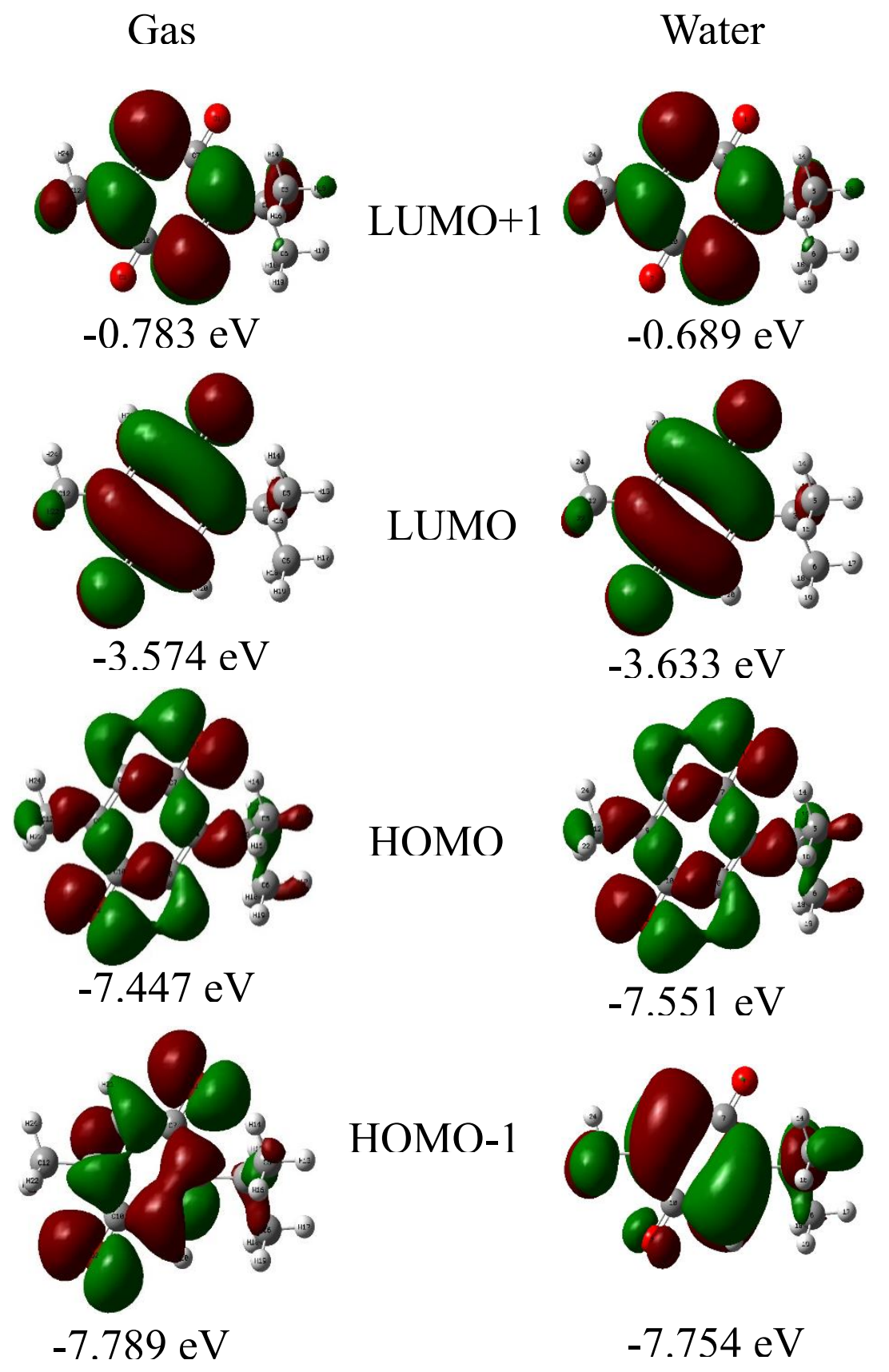

Figure 3. LUMO+1, LUMO, HOMO and HOMO-1 frontier orbitals of TQ calculated in the gas and water phases at B3LYP/6-311+G (d,p) level of theory 

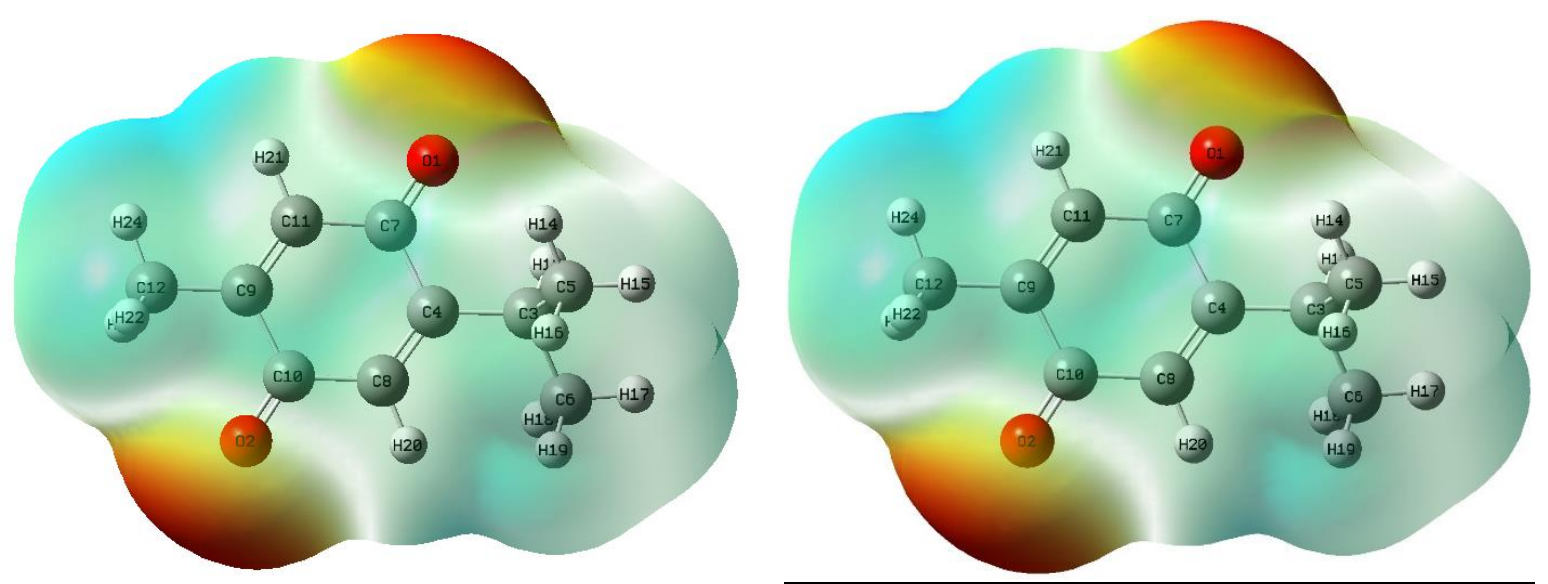

$-5.021 \mathrm{e}-2$

Figure 4. Molecular electrostatic potential (MEP) surface of TQ molecule in gas (left) and water (right) calculated at B3LYP/6-311+G(d,p) level of theory

\section{Thermodynamically favored mechanism}

In order to investigate the antioxidant activity and mechanism of TQ, Gibbs free energy and enthalpy changes of the hydrogen abstraction (HA) from TQ to $\mathrm{OH}^{\bullet}$ radical have been computed from the theoretically data of optimized geometry of the concerned reactants and products as per the simple principle of thermochemistry. The calculated $\Delta \mathrm{G}$ and $\Delta \mathrm{H}$ values for various $\mathrm{CH}$ groups of TQ against $\mathrm{OH}^{\bullet}$ radical are shown in table 6 . It is very interesting to report that, all the $\Delta \mathrm{G}$ and $\Delta \mathrm{H}$ calculated here are negative for the HA reaction which is in favor of antioxidant power of TQ through HAT mechanism. The lowest $\Delta \mathrm{G}$ and $\Delta \mathrm{H}$ were observed for 3CH group in all cases studied here which is in good consistent with other thermochemical parameters such as BDE, PDE and PA discussed in the earlier sections. In addition to this, from the table 6 it can easily be seen that, the order of $\Delta \mathrm{G}$ and $\Delta \mathrm{H}$ values for the studied four $\mathrm{CH}$ groups of TQ molecule are around similar as BDE, PDE and PA in both gas and water media. The values of $\Delta \mathrm{G}$ and $\Delta \mathrm{H}$ for the $\mathrm{OH}^{\bullet}$ radical scavenging reaction $\left(\mathrm{TQ}+\mathrm{OH}^{\bullet}=\mathrm{TQ}^{\bullet}+\mathrm{H}_{2} \mathrm{O}\right.$ ) are within the range of -17.50 to -40.61 and 15.95 to $-38.74 \mathrm{kcal} / \mathrm{mole}$ respectively in gas and -19.14 to $-43.54 \mathrm{kcal} / \mathrm{mole}$ and -15.88 to $-40.34 \mathrm{kcal} / \mathrm{mole}$ respectively in water. The $\Delta \mathrm{G}$ of $\mathrm{HA}$ from $3 \mathrm{CH}$ group and $12 \mathrm{CH}_{3}$ groups of TQ to $\mathrm{OH}^{\bullet}$ radical are -40.61 and -32.29 in gas, and -43.54 and $-35.39 \mathrm{kcal} / \mathrm{mole}$ in water respectively which are significantly lower than the literature value. Similarly the calculated $\Delta \mathrm{H}$ values of $\mathrm{HA}$ reaction of TQ are remarkably less than the literature values abovementioned. The negative and less values of $\Delta \mathrm{G}$ and $\Delta \mathrm{H}$ for $\mathrm{OH}^{\bullet}$ radical scavenging reaction thermodynamically 
provide apposite support toward the antioxidant potentiality of TQ as free radical scavenger via HAT. On the other hand, the values of $\Delta \mathrm{G}$ and $\Delta \mathrm{H}$ for electron transfer reaction $\left((\mathrm{TQ}-\mathrm{H})+\mathrm{OH}^{\bullet}=(\mathrm{TQ}-\mathrm{H})^{\bullet}+\mathrm{OH}^{-}\right)$from TQ to $\mathrm{OH}^{\bullet}$ radical to form $\mathrm{OH}^{-}$ion are positive in both media which deliver less potency of TQ to this mechanism of action.

Table 6. Changes of Gibbs free energies ( $\Delta \mathrm{G} \mathrm{kcal} / \mathrm{mole}$ ) and enthalpies ( $\Delta \mathrm{H} \mathrm{kcal} / \mathrm{mole}$ ) related to the reactions of TQ toward $\mathrm{HO}^{\bullet}$ radical calculated in the gas phase and water at $\mathrm{B} 3 \mathrm{LYP} / 6-311+\mathrm{G}(\mathrm{d}, \mathrm{p})$ level of theory

\begin{tabular}{|c|c|c|c|c|c|c|c|c|}
\hline \multirow[t]{3}{*}{ Radical species } & \multicolumn{2}{|c|}{$\Delta \mathrm{G}, \mathrm{kcal} / \mathrm{mole}$} & \multicolumn{2}{|c|}{$\Delta \mathrm{H}, \mathrm{kcal} / \mathrm{mole}$} & \multicolumn{2}{|c|}{$\Delta \mathrm{G}, \mathrm{kcal} / \mathrm{mole}$} & \multicolumn{2}{|c|}{$\begin{array}{c}\Delta \mathrm{H} \\
\mathrm{kcal} / \mathrm{mole}\end{array}$} \\
\hline & \multicolumn{4}{|c|}{ (for hydrogen abstraction to $\mathrm{OH}^{\bullet}$ ) } & \multicolumn{4}{|c|}{ (for electron transfer to $\mathrm{OH}^{\bullet}$ ) } \\
\hline & Gas & Water & Gas & Water & Gas & Water & Gas & Water \\
\hline $3 \mathrm{CH}$ & -40.61 & -43.54 & -38.74 & -40.34 & & & & \\
\hline $12 \mathrm{CH}_{3}$ & -32.92 & -35.39 & -32.46 & -33.07 & & & & \\
\hline $5 \mathrm{CH}_{3}$ & -17.29 & -19.14 & -15.89 & -15.99 & 156.73 & 157.29 & 47.76 & 48.42 \\
\hline $6 \mathrm{CH}_{3}$ & -17.50 & -19.18 & -15.95 & -15.88 & & & & \\
\hline \multirow{2}{*}{ References } & $-24.2[49]$ & $-31.7[49]$ & $-22.0[49]$ & $-29.4[49]$ & & & & \\
\hline & $-9.37[31]$ & $-11.26[31]$ & & & & & & \\
\hline
\end{tabular}

\section{Conclusion}

Antioxidant activity of TQ, a non-phenolic molecule has been successfully evaluated in gas and water phases using DFT calculation. The observed information revealed that, the studied compound can pose as stronger antioxidant as other available ones. In both gas and water, $3 \mathrm{CH}$ and $12 \mathrm{CH}_{3}$ positions are thermodynamically more feasible to scavenge free radical in comparison to $5 \mathrm{CH}_{3}$ and $6 \mathrm{CH}_{3}$ groups studied here. In this regard, HAT mechanism is preferable than SETPT and SPLET pathways. Obtained results clearly exhibit free radical scavenging potential of TQ molecule without possessing any phenolic group in its structure, which paves the way for other such compounds to be searched for their antioxidant power.

\section{Funding}

The authors did not take fund from any authority. 


\section{Conflicts of interest/Competing interests}

No conflicts of interest/competing interests.

\section{Availability of data and material}

All the data are provided in the manuscript and supplementary file.

\section{Code availability}

Not applicable

\section{Authors' contributions}

Jewel Hossen: Conceptualization; Data curation; Formal analysis; Methodology; Visualization; Writing - original draft; Editing; M. Abbas Ali: Editing and reviewing; Sultanur Reza: reviewing.

\section{Ethics approval}

The articles has not been submitted to elsewhere.

\section{Consent to participate}

All the authors actively participated in this work.

\section{Consent for publication}

If this manuscript is accepted for publication in this journal, we would not withdraw it.

\section{References}

1. Niki E (2016) Antioxidant capacity of foods for scavenging reactive oxidants and inhibition of plasma lipid oxidation induced by multiple oxidants. Food \& function 7:2156-2168

2. Antonchenko VY, Kryachko ES (2005) Structural, energetic, and spectroscopic features of lower energy complexes of superoxide hydrates O2-(H2O) 1-4. Journal of Physical Chemistry A 109:3052-3059. https://doi.org/10.1021/jp046498z

3. Çakmak E, Özbakır Işın D (2020) A theoretical evaluation on free radical scavenging activity of 3styrylchromone derivatives: the DFT study. Journal of Molecular Modeling 26:1-11. 
https://doi.org/10.1007/s00894-020-04368-7

4. Neha K, Haider M, Pathak A, et al (2019) Medicinal prospects of antioxidants: A review. European Journal of Medicinal Chemistry 178:687-704

5. Valko M, Rhodes C, Moncol J, et al (2006) Free radicals, metals and antioxidants in oxidative stressinduced cancer. Chemico-biological interactions 160:1-40

6. Mokini Z, Marcovecchio M, Clinical FC-D research and, 2010 U (2010) Molecular pathology of oxidative stress in diabetic angiopathy: role of mitochondrial and cellular pathways. Diabetes research and clinical practice $87: 313-321$

7. Staniek K, Gille L (2010) Is thymoquinone an antioxidant? BMC Pharmacology 10:1-1. https://doi.org/10.1186/1471-2210-10-s1-a9

8. Chiuh Woo C, Prem Kumar A, Sethi G, et al (2011) Thymoquinone: Potential cure for inflammatory disorders and cancer. Biochemical pharmacology 83:443-451. https://doi.org/10.1016/j.bcp.2011.09.029

9. Zheng W, Wang SY (2001) Antioxidant activity and phenolic compounds in selected herbs. Journal of Agricultural and Food Chemistry 49:5165-5170. https://doi.org/10.1021/jf010697n

10. Rice-Evans CA, Miller NJ, Paganga G (1997) Antioxidant properties of phenolic compounds. Trends in Plant Science 2:152-159

11. Tohma H, Gülçin İ, Bursal E, et al (2017) Antioxidant activity and phenolic compounds of ginger (Zingiber officinale Rosc.) determined by HPLC-MS/MS. Journal of Food Measurement and Characterization 11:556566. https://doi.org/10.1007/s11694-016-9423-z

12. Mussatto SI, Ballesteros LF, Martins S, Teixeira JA (2011) Extraction of antioxidant phenolic compounds from spent coffee grounds. Separation and Purification Technology 83:173-179.

https://doi.org/10.1016/j.seppur.2011.09.036

13. Baschieri A, Ajvazi MD, Tonfack JLF, et al (2017) Explaining the antioxidant activity of some common non-phenolic components of essential oils. Food Chemistry 232:656-663.

https://doi.org/10.1016/j.foodchem.2017.04.036

14. Vo Q, Nam P, Bay M Van, et al (2018) Density functional theory study of the role of benzylic hydrogen atoms in the antioxidant properties of lignans. Scientific reports 8:1-10

15. Ngo TC, Dao DQ, Thong NM, Nam PC (2016) Insight into the antioxidant properties of non-phenolic 
terpenoids contained in essential oils extracted from the buds of Cleistocalyx operculatus: a DFT study. RSC Advances 6:30824-30834. https://doi.org/10.1039/C6RA02683D

16. Khither H, Sobhi W, Khenchouche A, et al (2018) In-vitro Antioxidant Effect of Thymoquinone. Annual Research \& Review in Biology 25:1-9. https://doi.org/10.9734/arrb/2018/40165

17. Yildiz S, Turan S, Kiralan M, Ramadan MF (2020) Antioxidant properties of thymol, carvacrol, and thymoquinone and its efficiencies on the stabilization of refined and stripped corn oils. Journal of Food Measurement and Characterization 15:1-12. https://doi.org/10.1007/s11694-020-00665-0

18. Shao Y, Li B, Huang Y, et al (2017) Thymoquinone attenuates brain injury via an antioxidative pathway in a status epilepticus rat model. Translational neuroscience 8:9-14

19. Kassab R, El-Hennamy R (2017) The role of thymoquinone as a potent antioxidant in ameliorating the neurotoxic effect of sodium arsenate in female rat. Journal of Basic and Applied Sciences 4:160-167

20. Xue Y, Zheng Y, An L, et al (2014) Density functional theory study of the structure-antioxidant activity of polyphenolic deoxybenzoins. Food chemistry 151:198-206

21. Chen Y, Xiao H, Zheng J, Liang G (2015) Structure-thermodynamics-antioxidant activity relationships of selected natural phenolic acids and derivatives: An experimental and theoretical evaluation. PLoS ONE 10:e0121276. https://doi.org/10.1371/journal.pone.0121276

22. Zheng YZ, Chen DF, Deng G, et al (2018) The surrounding environments on the structure and antioxidative activity of luteolin. Journal of Molecular Modeling 24:1-18. https://doi.org/10.1007/s00894-018-3680-1

23. Kumer A, Sarkar N, Paul S, Zannat A (2019) The Theoretical Prediction of Thermophysical properties, HOMO, LUMO, QSAR and Biological Indics of Cannabinoids (CBD) and Tetrahhdrocannabinol (THC) by Computational Chemistry. Advanced Journal of Chemistry-Section A 2:190-202.

https://doi.org/10.33945/sami/ajca.2019.2.190202

24. Janak JF (1978) Proof that $\partial \mathrm{E} \partial \mathrm{ni}=\varepsilon$ in density-functional theory. Physical Review B 18:7165-7168. https://doi.org/10.1103/PhysRevB.18.7165

25. Parr RG, Pearson RG (1983) Absolute Hardness: Companion Parameter to Absolute Electronegativity. Journal of the American Chemical Society 105:7512-7516. https://doi.org/10.1021/ja00364a005

26. Pearson RG (1988) Absolute Electronegativity and Hardness: Application to Inorganic Chemistry. Inorganic Chemistry 27:734-740. https://doi.org/10.1021/ic00277a030 
27. Becke, A A (1988) Density-functional exchange-energy approximation with correct asymptotic behavior. Physical review A 38:3098

28. Mikulski D, Molski M (2010) Quantitative structure-antioxidant activity relationship of trans-resveratrol oligomers, trans-4,4'-dihydroxystilbene dimer, trans-resveratrol-3-O-glucuronide, glucosides: Trans-piceid, cis-piceid, trans-astringin and trans-resveratrol-4'-O- $\beta$-D-glucopyranoside. European Journal of Medicinal Chemistry 45:2366-2380. https://doi.org/10.1016/j.ejmech.2010.02.016

29. Praveena R, Sadasivam K, Deepha V (2014) Antioxidant potential of orientin: a combined experimental and DFT approach. Journal of Molecular Structure 1061:114-123

30. Boulebd H (2020) The role of benzylic-allylic hydrogen atoms on the antiradical activity of prenylated natural chalcones: a thermodynamic and kinetic study. Journal of Biomolecular Structure and Dynamics 110. https://doi.org/10.1080/07391102.2020.1740791

31. Boulebd H (2020) Theoretical insights into the antioxidant activity of moracin T. Free Radical Research 54:221-230. https://doi.org/10.1080/10715762.2020.1747616

32. Bizarro MM, Cabral BJC, Borges RM, et al (1999) Substituent effects on the O-H bond dissociation enthalpies in phenolic compounds: agreements and controversies

33. Wright JS, Johnson ER, DiLabio GA (2001) Predicting the activity of phenolic antioxidants: Theoretical method, analysis of substituent effects, and application to major families of antioxidants. Journal of the American Chemical Society 123:1173-1183. https://doi.org/10.1021/ja002455u

34. Rimarčík J, Lukeš V, Klein E, et al (2010) Study of the solvent effect on the enthalpies of homolytic and heterolytic $\mathrm{N}-\mathrm{H}$ bond cleavage in p-phenylenediamine and tetracyano-p-phenylenediamine. Journal of Molecular Structure: THEOCHEM 952:25-30

35. Parker VD (1992) Homolytic Bond (H-A) Dissociation Free Energies in Solution. Applications of the Standard Potential of the $(\mathrm{H}+/ \mathrm{H} \cdot)$ Couple. Journal of the American Chemical Society 114:7458-7462. https://doi.org/10.1021/ja00045a018

36. Mikulski D, Górniak R, Chemistry MM (2010) A theoretical study of the structure-radical scavenging activity of trans-resveratrol analogues and cis-resveratrol in gas phase and water environment. European journal of medicinal chemistry 45:1015-1027

37. Amić A, Lučić B, Stepanić V, et al (2017) Free radical scavenging potency of quercetin catecholic colonic 
metabolites: Thermodynamics of $2 \mathrm{H}+/ 2 \mathrm{e}^{-}$- processes. Food chemistry 218:144-151

38. Sadasivam K, Kumaresan R (2011) Antioxidant behavior of mearnsetin and myricetin flavonoid compounds - A DFT study. Spectrochimica Acta - Part A: Molecular and Biomolecular Spectroscopy 79:282-293. https://doi.org/10.1016/j.saa.2011.02.042

39. Mendes RA, Barboza CA, Brown A, et al (2018) A computational investigation on the antioxidant potential of myricetin 3,4'-di-O- $\alpha$-L-rhamnopyranoside Ab Initio Study on Photophysics of Tris(salicylideneanilines) View project Excited Electronic States of Cyanides View project A computational investigat. Article in Journal of Molecular Modeling 24:1-10. https://doi.org/10.1007/s00894-018-3663-2

40. Mohamad S, Nazifi R (2019) Antioxidant properties of Aloe vera components: a DFT theoretical evaluation. Taylor \& Francis 53:922-931. https://doi.org/10.1080/10715762.2019.1648798

41. Mendes RA, Almeida SKC, Soares IN, et al (2019) Evaluation of the antioxidant potential of myricetin 3-O$\alpha$-L-rhamnopyranoside and myricetin 4'-O- $\alpha$-L-rhamnopyranoside through a computational study. Journal of Molecular Modeling 25:1-12. https://doi.org/10.1007/s00894-019-3959-X

42. Justino GC, Vieira AJSC (2010) Antioxidant mechanisms of quercetin and myricetin in the gas phase and in solution- A comparison and validation of semi-empirical methods. Journal of Molecular Modeling 16:863876. https://doi.org/10.1007/s00894-009-0583-1

43. Shang Y, Zhou H, Li X, et al (2019) Theoretical studies on the antioxidant activity of viniferifuran. New Journal of Chemistry 43:15736-15742.

44. De Abreu HA, Aparecida dos S. Lago I, Souza GP, et al (2008) Antioxidant activity of (+)-bergenin-a phytoconstituent isolated from the bark of Sacoglottis uchi Huber (Humireaceae). Organic \& Biomolecular Chemistry 6:2713-2718. https://doi.org/10.1039/b804385j

45. Eberle B, Hübner O, Ziesak A, et al (2015) What makes a strong organic electron donor (or Acceptor)? Chemistry - A European Journal 21:8578-8590. https://doi.org/10.1002/chem.201406597

46. Zheng YZ, Deng G, Liang Q, et al (2017) Antioxidant activity of quercetin and its glucosides from propolis: A theoretical study. Scientific Reports 7:1-11. https://doi.org/10.1038/s41598-017-08024-8

47. Siyamak Shahab, Masoome Sheikhi (2020) Antioxidant Properties of the Phorbol: A DFT Approach. Russian Journal of Physical Chemistry B 14:15-18. https://doi.org/10.1134/S1990793120010145

48. Galano A (2015) Free Radicals Induced Oxidative Stress at a Molecular Level: The Current Status, 
Challenges and Perspectives of Computational Chemistry Based Protocols. Journal of the Mexican

Chemical Society 59:231-262

49. Li M, Liu W, Peng C, et al (2013) A DFT study on reaction of eupatilin with hydroxyl radical in solution. International Journal of Quantum Chemistry 113:966-974. https://doi.org/10.1002/qua.24060 
Figures
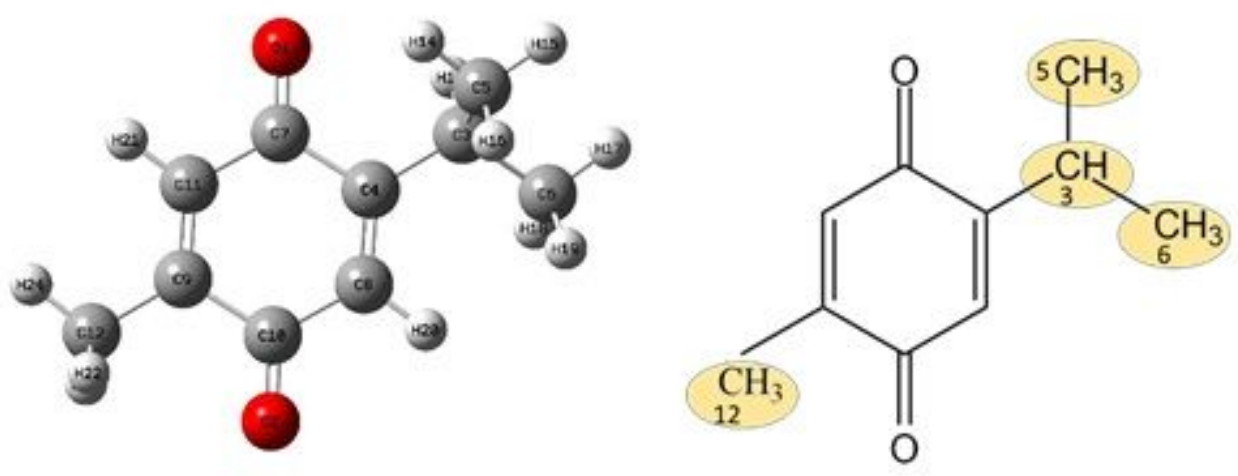

Figure 1

Optimized (left) and schematic structures of TQ and possible groups considered for antioxidant action (right)

Radical

Gas

Water

group

$3 \mathrm{CH}$
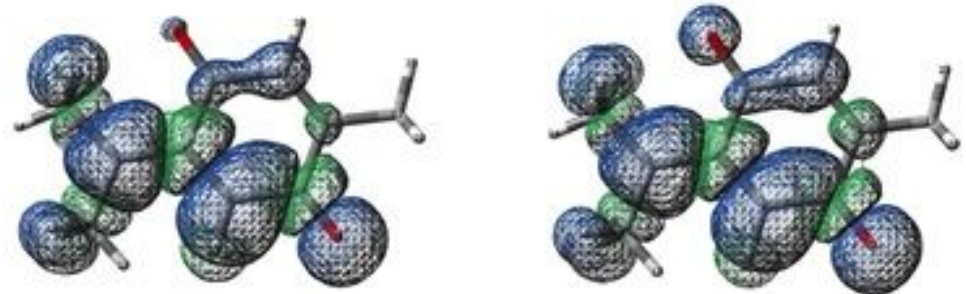

$12 \mathrm{CH}_{3}$
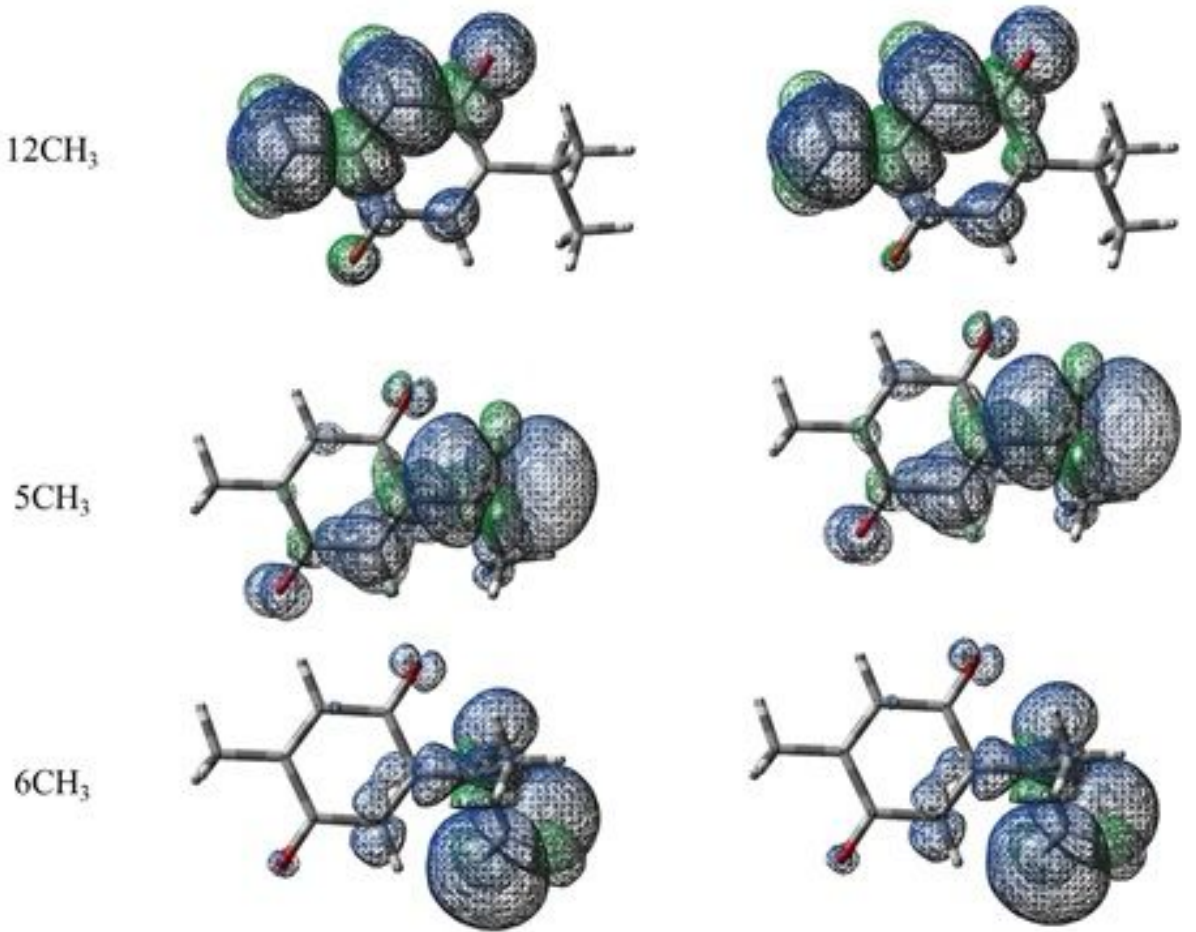

Figure 2 
Spin density distribution of the radicals formed after elimination of hydrogen atom from the functional groups concerned.
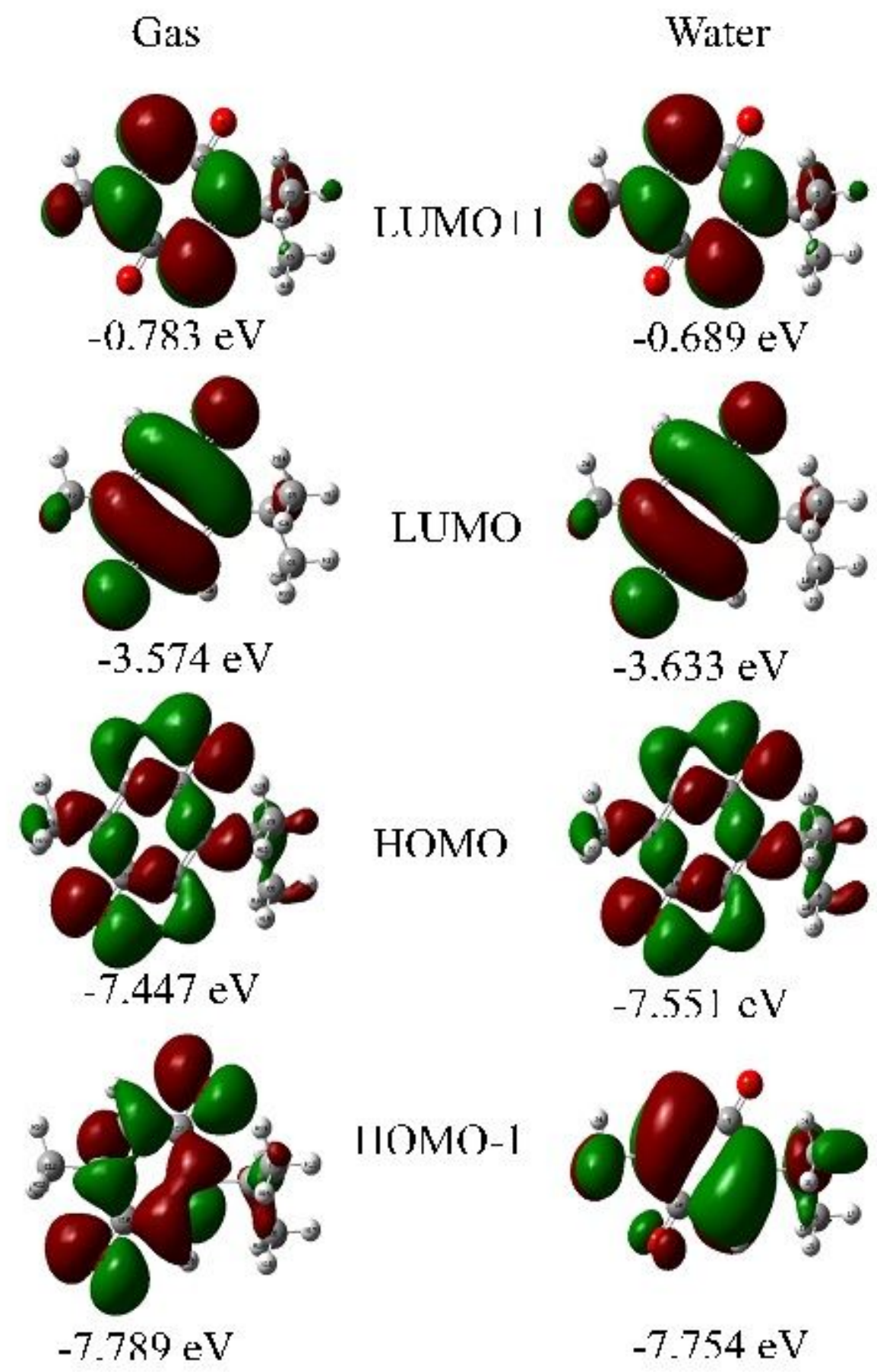

\section{HOMO}
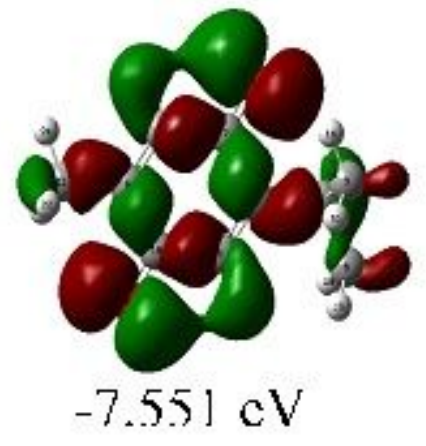

IIOMO-I

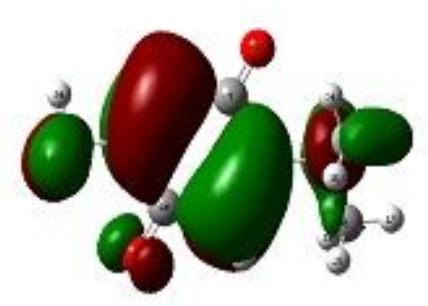

$-7.754 \mathrm{eV}$

Figure 3

LUMO+1, LUMO, HOMO and HOMO-1 frontier orbitals of TQ calculated in the gas and water phases at $B 3 L Y P / 6-311+G(d, p)$ level of theory 

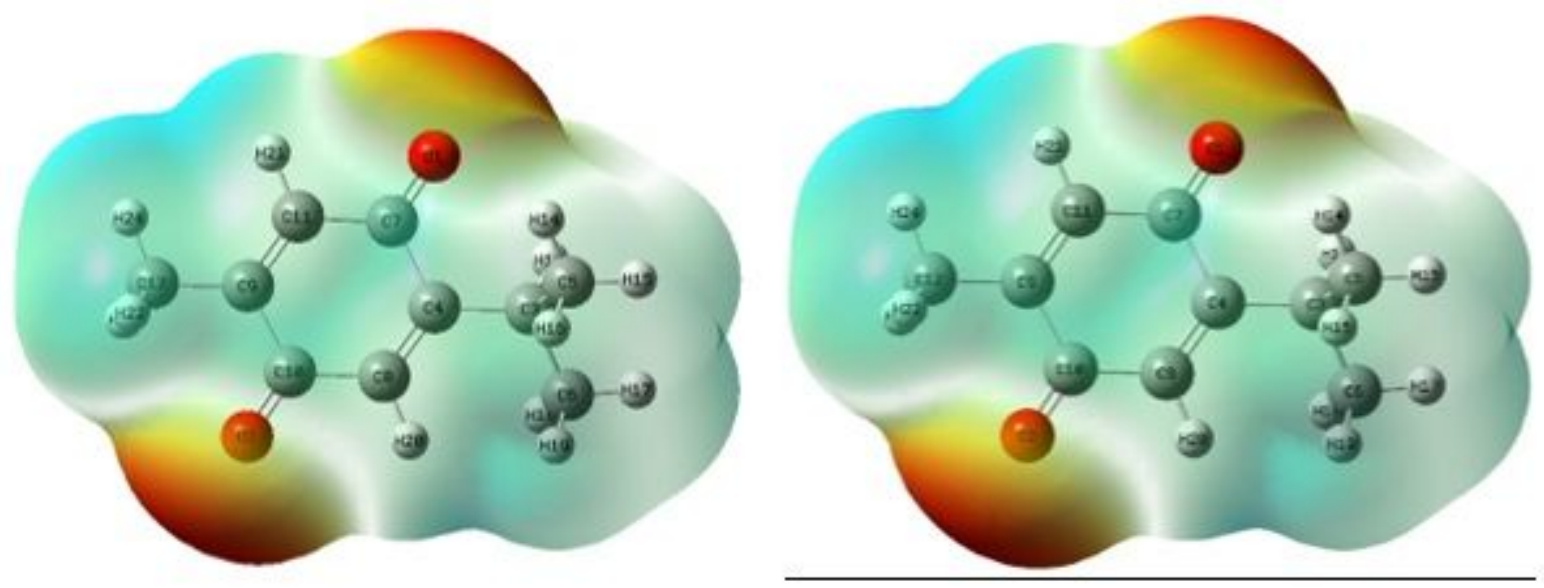

SARE-2

\section{Figure 4}

Molecular electrostatic potential (MEP) surface of TQ molecule in gas (left) and water (right) calculated at $B 3 L Y P / 6-311+G(d, p)$ level of theory

\section{Supplementary Files}

This is a list of supplementary files associated with this preprint. Click to download.

- Supplementalfile.docx 